www.jmscr.igmpublication.org

Impact Factor (SJIF): 6.379

Index Copernicus Value: 79.54

ISSN (e)-2347-176x ISSN (p) 2455-0450

crossrefDOI: https://dx.doi.org/10.18535/jmscr/v6i9.96

Journal Of Medical Science And Clinical Research

\title{
Study of cytomorphological spectrum of various thyroid lesions and reporting under bethesda system in tertiary care centre
}

\author{
Authors \\ Dr Debaleena Dev Barman ${ }^{1}$, Dr Alpana Banerjee ${ }^{2}$ \\ ${ }^{1}$ Tutor, Department of Pathology, Agartala Government Medical College and GB Pant Hospital, Agartala, \\ Tripura (west) \\ ${ }^{2}$ Assistant Professor, Department of Pathology, Agartala Government Medical College and GB Pant \\ Hospital
}

\begin{abstract}
Background: This study has attempted to standardize reporting and cytological criteria in aspiration smears of thyroid swellings with the help of Bethesda System for Reporting Thyroid Cytopathology (TBSRTC).

Aims: The objective of this study is to categorise the thyroid cytology smears by TBSRTC, to analyze cytological features in details and to correlate the cytopathology with histopathology, wherever surgery is done.

Materials and Methods: This was a retrospective study of 617 fine needle aspirations (FNA) of thyroid swellings. All fine needle aspiration cytology (FNAC) diagnoses were classified according to the features given in the monograph of TBSRTC into non diagnostic/unsatisfactory (ND/UNS), benign, atypia of undetermined significancelfollicular lesion of undetermined significance (AUS/FLUS), follicular neoplasm/suspicious of a follicular neoplasm (FN/SFN), suspicious for malignancy (SFM), and malignant. Cytohistological correlation was done, when surgical material was available.

Results: The distribution of various categories from 619 evaluated thyroid swellings was as follows: 9.5\% ND/UNS, 74\% benign, $4.9 \%$ AUS/FLUS, 3.2\% FN, 0.6\% SFM, and 6.1\% malignant.

Conclusion: TBSRTC is an excellent reporting system for thyroid FNA. It also provides clear management guidelines to clinicians to go for follow-up FNA or surgery and also the extent of surgery. Thyroid cytology can provide a definite diagnosis of malignancy, with tumour type, enabling appropriate therapeutic surgery in one stage.
\end{abstract}

\section{Introduction}

Thyroid disorders are the most common endocrine disorders worldwide, including India. Fine needle aspiration cytology (FNAC) of thyroid occupies an extremely important role worldwide. This minimally invasive and cost-effective technique is extremely useful in identifying a substantial proportion of thyroid nodules as benign and reducing unnecessary surgery for patients with benign diseases ${ }^{1}$. Before the routine use of thyroid FNA, the percentage of surgically resected thyroid nodules that were malignant was $14 \%{ }^{(2)}$. With current thyroid FNA practice, the percentage of resected nodules that are malignant surpasses 50\% (3). Since the incidence of thyroid malignancy is relatively low and only 1 in 20 clinically identified 
nodules are malignant, thyroid fine needle aspiration (FNA) can help to reduce the rate of surgery for benign thyroid disease ${ }^{(4)}$. Historically, terminology for thyroid FNA has varied significantly from one laboratory to another, creating confusion in some cases and hindering the sharing of clinically meaningful data among various institutions. The NCI conference participants acknowledged the importance of developing a uniform terminology for reporting thyroid FNA result. $^{(5)}$

A monograph "The Bethesda System for Reporting Thyroid Cytopathology" (TBSRTC) which includes definitions, diagnostic/ morphologic criteria, explanatory notes, and a brief management plan for each diagnostic category was published. ${ }^{(5)}$

The objective of the present retrospective study done in Agartala government medical college was to analyse thyroid cytology smears by TBSRTC into various diagnostic categories, describe their cytological features and correlate with histological features wherever resected thyroid specimens were received.

\section{Materials and Methods}

This was a retrospective study of all cases with thyroid swelling referred to the Department of Pathology, Agartala Government medical college and Hospital, Agartala, Tripura (west), for FNAC during the period from March 2012 to February 2017. Relevant clinical histories along with age, gender, caste of each patient were collected from the record. All patients were subjected to FNA sampling using Zajdela technique ${ }^{[6]}$. The smears were prepared using conventional methods and stained with Leishman stains. All slides were retrieved from the archive and microscopic examination done by both the authors simultaneously. The cytological features were evaluated and the reporting was done according to TBSRTC (Table-1). The morphological criteria given in the monograph of TBSRTC were used ${ }^{[5]}$. All the parameters were calculated either excluding FN/SFN or including it with either benign or malignant diagnosis to highlight the effect on statistical values.

\section{Data collection}

All thyroid cytopathological slides and ultra sound of thyroid reports were reviewed and classified according to the BSRTC system. Age, gender, caste, cytological diagnosis and in few cases histological diagnosis were collected from patients record book and cytopathology reports.

\section{Bethesda system}

In the present study, the Bethesda system of reporting thyroid cytology (TBSRTC) is used for reporting FNAC of thyroid. All fine needle aspiration cytology (FNAC) diagnoses were classified according to the features given in the monograph of TBSRTC into nondiagnostic/ unsatisfactory (ND/UNS), benign, atypia of undetermined significance/follicular lesion of undetermined significance (AUS/FLUS), follicular neoplasm/suspicious of a follicular neoplasm (FN/SFN), suspicious for malignancy (SFM), and malignant. ${ }^{(3)}$

Table 1 The Bethesda system ${ }^{(3)}$

$\begin{array}{lc}\text { Diagnostic category } & \text { Cytological diagnosis } \\ \text { I } & \text { Nondiagnostic or unsatisfactory } \\ \text { II } & \text { Benign } \\ \text { III } & \text { AUS/FLUS } \\ \text { IV } & \text { FNS/SFN } \\ \text { V } & \text { Suspicious for malignancy } \\ \text { VI } & \text { Malignant }\end{array}$

Risk of malignancy, $\%$
$1-4$
$0-3$
$5-15$
$15-30$
$60-75$
$97-99$

Usual management

Repeat FNA with ultrasound guidance

Clinical follow-up

Repeat FNA

Surgical lobectomy

Near-total thyroidectomy or surgical

Near-total thyroidectomy 
All patients were subjected to FNA sampling using Zajdela technique ${ }^{[6]}$. The smears were prepared using conventional methods and stained with Leishman stains. All slides were retrieved from the archive and examined microscopically by both authors and discussed. The cytological features were evaluated and categorised according to TBSRTC.

\section{Diagnostic criteria}

An adequate sample must be representative of the lesion (the specimen is taken from the appropriate location) and adequate in amount. Smear is considered "adequate," when: 5-6 groups of wellpreserved follicular epithelial cells with 10 or more cells/ group; 10 large clusters of follicular epithelial cells with more than 20 cells each; 6 groups of follicular epithelial cells on at least 2 of 6 aspirates; and at least 8-10 tissue fragments of well-preserved follicular epithelium on each of two slides, for a total of at least six properly prepared thin cell spreads from multiple punctures of the nodule. ${ }^{[7]}$

In addition, the smear should be technically well prepared; the aspirate should be promptly thinly smeared to avoid clotting and processed according to the stains used. Last, the smear should be read in the clinical context because certain lesions, such as cysts and colloidal Goiter, yield specimens with very few cells, material that would be considered cytologically non-diagnostic but that is consistent with the clinical impression. ${ }^{(8)}$

\section{Results}

During the study period, 619 thyroid FNAC cases were found. Most of the thyroid swelling 309 out of 619 i.e. $49.9 \%$ were present in the age group between 20-40yrs of age and 217 out of 619 i.e. $35 \%$ were present in the age group of 40-60 years. A total of 533 cases $(86.1 \%)$ were female and 76 cases $(12.2 \%)$ were male, with female to male ratio of $7: 1$. (Table-2)

The age distribution pattern of the study revealed that the maximum number of thyroid swelling (49.9\%) was seen in the $20-40$ year age range. The minimum number was in the youngest age group less than 20 years $(6.7 \%)$. Youngest patient was one and half years old and oldest was 75 years (Table-2).

In extremes of age, 42 out of $619(2 \%)$ is present in the age group of $<20$ years and 51 out of 619 i.e. $8.2 \%$ is present in the age group of $>60$ years. The distribution of 619 cases is shown in (Table6). Benign category was the largest (74\%) followed by Non Diagnostic/Unsatisfactory category (9.5\%), Malignant and Suspicious for malignancy categories constituted $6.1 \%$ and $0.6 \%$, respectively, making a total of $6.7 \%$.Atypia of undetermined significance/Follicular lesion of undermined significance constituted $3.2 \%$ cases, while Follicular neoplasm/Suspicious for follicular neoplasm had $8.2 \%$ cases and suspicious for malignancy representing $6.1 \%$ of all cases. The majority of diagnosis on FNAC was benign (74\%), and the remaining $9.5 \%$ were for unsatisfactory cases. Among the 38 cases reported as malignant, the female to male ratio was $7.0: 1$. (Table-3)

Among the benign thyroid swelling, most frequently encountered thyroid swellings are colloid goitre $(38.1 \%)$ followed by lymphocytic thyroiditis $(23.7 \%)$, the least encountered lesions being colloid goitre with hurthle cell change $(2.17 \%)$, granulomatous throiditids with follicular neoplasm (2.17\%) and aberrant thyroid cyst $(2.17 \%)$. Amongst the malignant lesions, Papillary carcinoma of thyroid was the most frequent at $33.33 \%$ followed by follicular neoplasm $25 \%$, the least common being non hodkins lymphoma $(4.16 \%)$ and medullary carcinoma (4.16\%). (Table-1)

The table shows out of 155 cases with colloid goitre-in which cystic changes was the most frequent- $44.4 \%$ followed by nodular goitre $33.3 \%$ and follicular cell hyperplasia- $22.2 \%$.

(Table-1)

In both females and males, most frequently encountered is colloid goitre $(38.1 \%)$ followed by lymphocytic thyroditis (23.8\%). Amongst the lymphocytic thyroiditis group of lesions, florid lymphocytic thyroiditis was the most frequent at 
$33.33 \%$ followed by associated hyperactivity $25 \%$ and hurthle cell change $16.66 \%$, the least common being associated with papillary carcinoma $(4.16 \%)$ and hurthle cell neoplasm(4.16\%). Anaplastic carcinoma is more common in males than in females. (Table-5)

The subcategory consistent with lymphocytic thyroiditis was $23.8 \%$ cases in benign category (figure-1). All specimens were moderately cellular. The lymphoid population was moderate in amount in $88.9 \%$ cases. The lymphoid cells were polymorphic. Intact lymphoid follicles and lymphohistiocytic aggregates were also seen. Hürthle cells (oncocytes) were present in all cases. Multinucleated giant cells were found in $24.6 \%$ cases and epithelioid cells in $16.1 \%$ cases.

In subcategory consistent with granulomatous thyroiditis(figure-2), there were $4.5 \%$ cases, which showed hypocellular smears with clusters of epithelioid histiocytes, that is, granulomas along with many multinucleated giant cells, lymphocytes, macrophages, and scant degenerated follicular cells.

In the ND/UNS category, 36 cases were subcategorized as cyst fluid only. There was 8 cases in subcategory virtually acellular specimen and $10 \%$ other (obscuring blood, clotting artefacts, etc.). (Table-6)

In benign category $54.7 \%$ of total cases were consistent with benign follicular nodule (BFN) (figure-4). It had follicular cells which were arranged predominantly in monolayer sheets or were occasionally intact, three dimensional, variably sized balls/spheres . Rare micro follicles were present. Anisonucleosis was seen in some cases but there was no significant pleomorphism or nuclear atypia. Cellularity was low to moderate; low cellularity was seen in $62.5 \%$ cases and moderate cellularity in $35.8 \%$ cases. High cellularity was not seen. Pleomorphism was present only in $1.9 \%$ cases out of 457 cases. Hürthle cells were present only in $0.6 \%$ cases. Foam cells (macrophages) were present in $32.2 \%$ cases.
Background was blood-mixed with colloid in $55.8 \%$ cases and was only colloid in $44.2 \%$ cases. Fire flare or spindle cell was not seen in any case of benign follicular nodule in this study.

In this study, category AUS/FLUS constituted $3.2 \%$. $80.8 \%$ of these prominently showed micro follicles in some but not all the moderately cellular smears, $6.1 \%$ prominently showed micro follicles with sparsely cellular smear with scant colloid, and $8.2 \%$ showed predominantly benign appearing smear with focal features of papillary thyroid carcinoma including nuclear grooves, enlarged nuclei with pale chromatin, and alterations in nuclear contour and shape.

$8.2 \%$ and $7 \%$ cases in were categorised under FN/SFN and FN, hurthle cell type respectively.

In the category Suspicious for malignancy, 4 cases were suspicious for papillary carcinoma and $12.5 \%$ were suspected for lymphoma and $12.5 \%$ were SFM, not otherwise specified (SFM, NOS). $66.6 \%$ cases of suspicious for papillary carcinoma(figure-5), were of Pattern A (patchy nuclear change), $16.7 \%$ cases were of Pattern B (incomplete nuclear change) and $16.7 \%$ cases were of Pattern D (cystic degeneration). There was no case of Pattern C (sparsely cellular specimen). 1 (12.5\%) case of subcategory suspicious for lymphoma cytologically showed cellular smear composed of numerous monomorphic small to intermediate sized lymphoid cells. In the subcategory SFM, NOS, there was only one case showing cytological features suggestive of malignancy, but they were not enough to categorize the type of malignancy.

Category malignant included 37 cases (6.1\%) cases. Most common was Papillary Thyroid Carcinoma detected in 28 cases $(75.6 \%)$. There were 4 cases $(10.8 \%)$ of anaplastic carcinoma and $2(5.4 \%)$ case of medullary thyroid carcinoma (MTC). In papillary carcinoma most common cytomorphological features are anatomical borders, papillary fragments and nuclear features and in few cases nuclear inclusions, psammoma bodies are found. (figure-5) 
Microscopic examination of the smears in two medullary carcinoma cases (Figure-6) showed cellular smears with dispersed as well as few clusters of plasmacytoid cells, spindle cells of variable sizes. The cells had eccentric nuclei with coarse chromatin and abundant amphophilic cytoplasm .Anisonucleosis, bi-nucleation and multi-nucleation was also noted. Small clumps of amyloid-like amorphous material were seen in the background, in leishman stain. Other case showing spindle cell population.

On FNAC, these tumors yielded a highly cellular aspirate containing large pleomorphic malignant cells. These malignant cells had either a macrophage like, spindle cell like or squamoid appearance. The background was mostly dirty with frequent necrotic debris and showed inflammation and scant colloid. In our study, 3 cases had muscle infiltration and all the cases with lymphatic emboli and cervical lymphadenopathy.

Among 617 cases 23 cases were thyroidectomy specimens. The most common variety was lymphocytic thyroiditis and colloid goitre followed by papillary carcinoma and medullary carcinoma.

Table- 1: Distribution of Thyroid Lesions in the Population of Tripura

\begin{tabular}{lc|}
\hline DISEASE & CASES \\
Colloid goitre & 155 \\
Colloid goitre with cystic changes & 51 \\
Colloid goitre with follicul ar cell & 8 \\
hyperpl asia & \\
Colloid goitre with follicul ar neopl asm & 1 \\
Colloid goitre with hurthle cell & 1 \\
hyperpl asia & \\
Nodular goitre & 20 \\
\hline Lymphocytic thyroi ditis & 126 \\
\hline Floridlymphocytic thyroiditis & 11 \\
\hline Lt with hyperactivity & 3 \\
\hline Lt with hurthle cell neoplasm & 1 \\
Lt with papillary cell hyperplasia & 2 \\
\hline Lt with hurthle cell change & 3 \\
\hline Lt with papca & 1 \\
\hline G ranulomatous thyr oiditis & 24 \\
G ranulomatous thyr oiditis with pap & 1 \\
hyperplasia & \\
G t with follicul ar cell hyperplasia & 1 \\
Thyroglossal cyst & 29 \\
Hyperplastic thyroid nodule & 20 \\
\hline Aberrant Thyroid cyst & 2 \\
\hline Hurthle cell neoplasm & 6 \\
Papca & 28 \\
Follicular neoplasm & 42 \\
Medullary carcinoma & 01 \\
\hline Adenom atous goi tre & 14 \\
Anaplastic carcinoma & 5 \\
NHI & 49 \\
Inconclusive & 619 \\
\hline TOTAI & \\
\hline & \\
\hline & \\
\hline
\end{tabular}

Table No-2: Distribution of Patients According to Age and Sex $(n=619)$

\begin{tabular}{|l|c|c}
$\begin{array}{l}\text { Age } \\
<20 \mathrm{yrs}\end{array}$ & $\begin{array}{c}\text { Male } \\
3\end{array}$ & $\begin{array}{c}\text { Female } \\
39\end{array}$ \\
\hline $20-40 \mathrm{yrs}$ & 38 & 271 \\
\hline $40-60 \mathrm{yrs}$ & 19 & 198 \\
\hline$>60 \mathrm{yrs}$ & 16 & 35 \\
TOTAL & 76 & 543 \\
\hline
\end{tabular}

Table-3: Distribution of Thyroid Lesions According to Sex $(n=619)$

\begin{tabular}{l|cc}
\hline & Male & Female \\
\hline Benign & 59 & 454 \\
\hline Malignant & 8 & 29 \\
Inconclusive & 9 & 50 \\
Total & 76 & 533
\end{tabular}

Table-4: Distribution of Thyroid Lesions According to Race $(\mathrm{N}=619)$

\begin{tabular}{l|l}
\hline COMMUNITY & $\%$ of cases \\
BENGALI & 489 \\
\hline TRIB AL POPULATION & 117 \\
\hline OTHERS & 13 \\
\hline Total & 619 \\
\hline
\end{tabular}

Table No-5: Cytomorphological Changes Observed in Lymphocytic Thyroiditis

\begin{tabular}{l|l}
\hline \multicolumn{2}{c}{ LYMPHOCY TIC THYROIDITIS WITH } \\
ASSOCIATED FEATURES
\end{tabular}


Table-6: Classification of Thyroid Lesion Diagnosed Lesion Diagnosed by FNAC Using TBSRTC (n=619) number

Cytological categories $\quad$ Subcategories $\quad \begin{gathered}\text { Number } \\ \text { of cases }\end{gathered} \quad \begin{gathered}\text { Total number of } \\ \text { cases in each } \\ \text { category }\end{gathered}$

\section{Cyst fluid only}

Virtually acellular specimen (ND/UNS)
36

8

$59(9.5)$

10

Consistent with benign follicular nodule (includes adenomatoid nodule, colloid nodule, etc.)

Consistent with lymphocytic (Hashimoto) thyroiditis in the proper clinical context

$457(74 \%)$

Consistent with granulomatous (subacute) thyroiditis

Other\{hyperplastic thyroid nodule, thyroglossal cyst,aberrant thyroid cyst\}
Suspicious for metastatic carcinoma
Suspicious for lymphoma
Other carcinoma

Suspicious for medullary carcinoma 
Undifferentiated (anaplastic) carcinoma

6

Malignant
Squamous cell carcinoma

Carcinoma with mixed features

Metastatic carcinoma

Non-Hodgkin lymphoma

Other
04

01

$38(6.1)$
Total

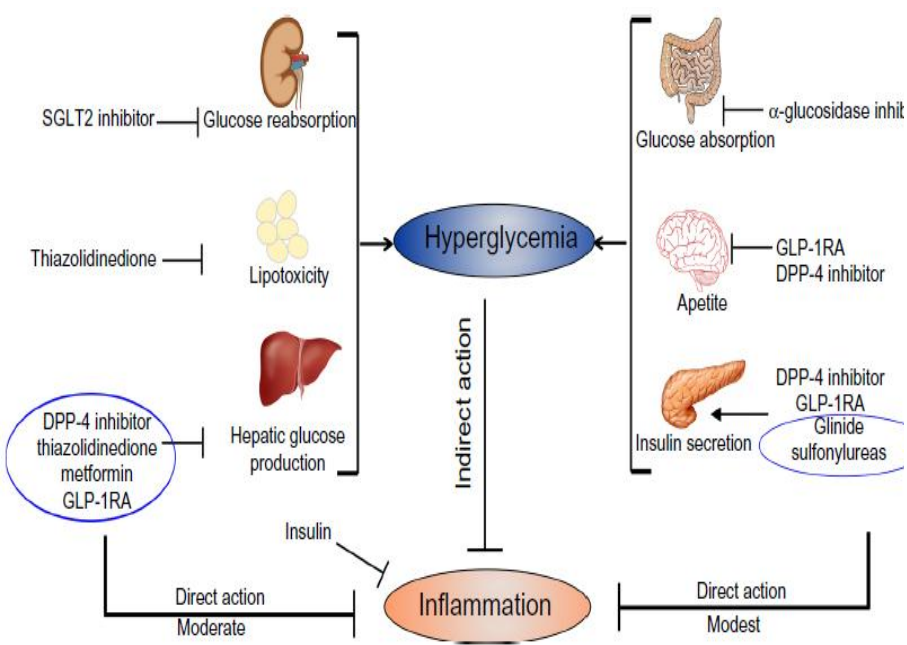

Figure 1: (a) Benign follicular nodule. Photomicrograph showing monolayer sheets of evenly spaced follicular cells having a honeycomb-like arrangement (arrow) (Smear, Giemsa, 400x magnification). (b) Benign follicular nodule. Photomicrograph showing globular mass of colloid with superimposed follicular cells (thick arrow) mixed with monolayer sheet of follicular cells (thin arrow) against the background of colloid and blood (Smear, Giemsa, 400x magnification). (c) Benign follicular nodule. Photomicrograph showing follicular cells arranged in sheets (honeycomblike) (thin arrow) mixed with macrophages (thick arrow) against the background of colloid (Smear, Giemsa, 400x magnification).
$619(100)$

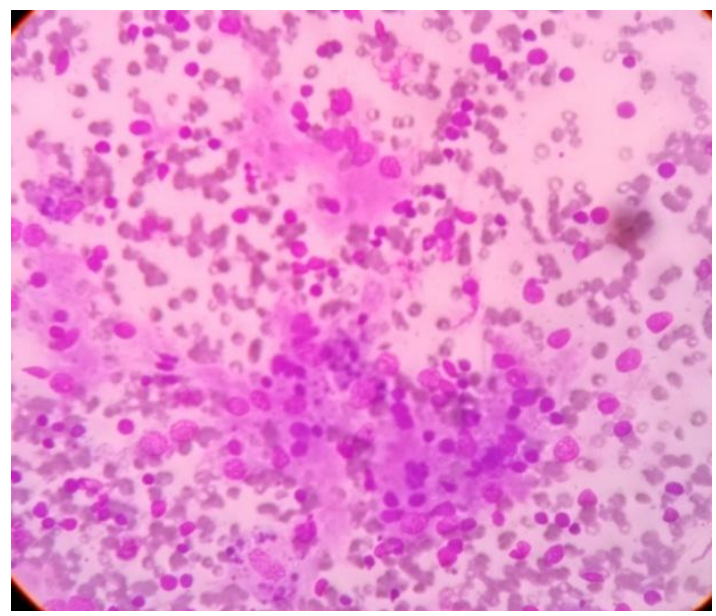

Figure 2: (a) Granulomatous (subacute) thyroiditis. Photomicrograph showing clusters of epithelioid histiocytes mixed with benign follicular cells(Smear, Giemsa, 400x magnification).

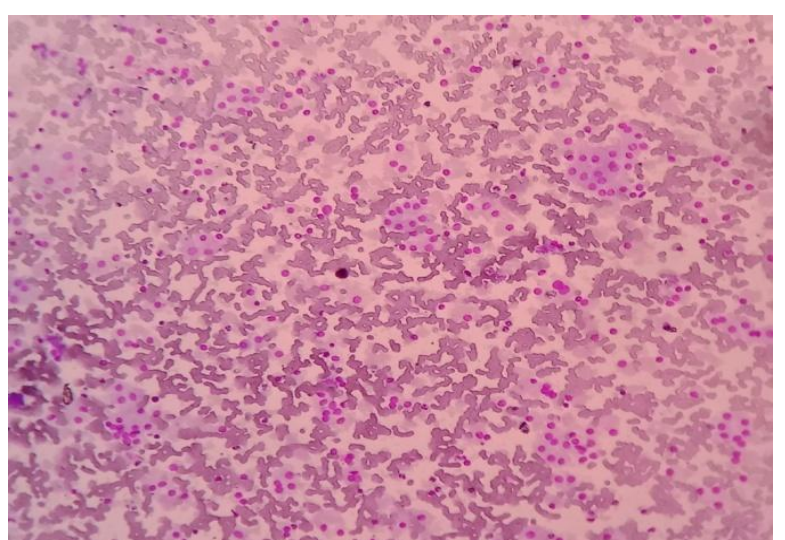

Figure 1 (b) Lymphocytic (Hashimoto) thyroiditis. Photomicrograph showing lymphohistiocytic aggregates in lymphocytic (Hashimoto) thyroiditis (Smear, Giemsa, 400x magnification). Intact lymphoid follicles and lymphohistiocytic aggregates were also seen. 


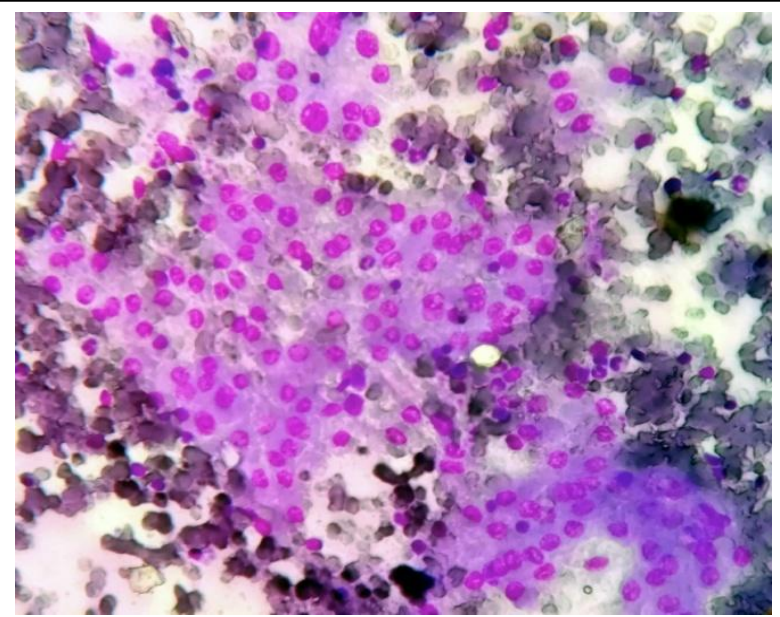

Figure 1(c)-photomicrograph shows follicular destruction by lymphocytes were also seen.

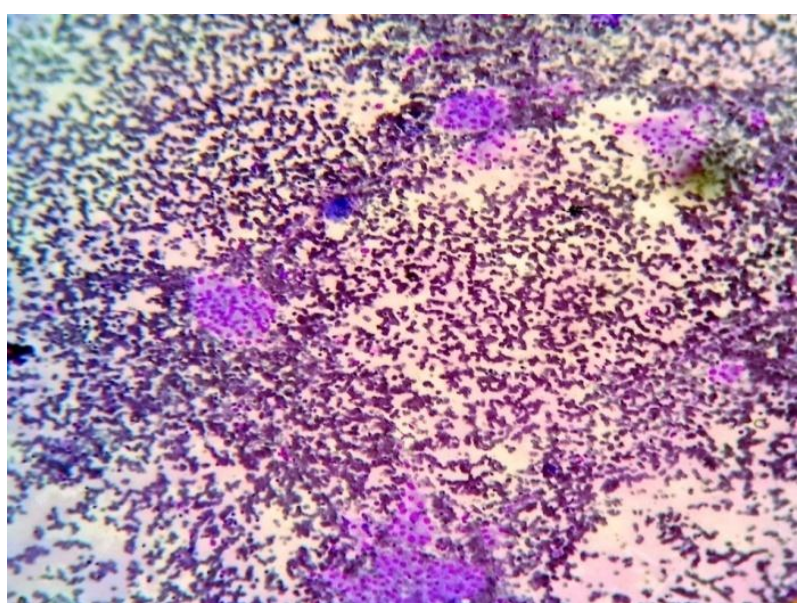

Figure 2: (a) Florid lymphocytic (Hashimoto) thyroiditis. Photomicrograph showing polymorphous lymphoid population (Smear, Giemsa, 400x magnification).

Lymphocytic (Hashimoto) thyroiditis.

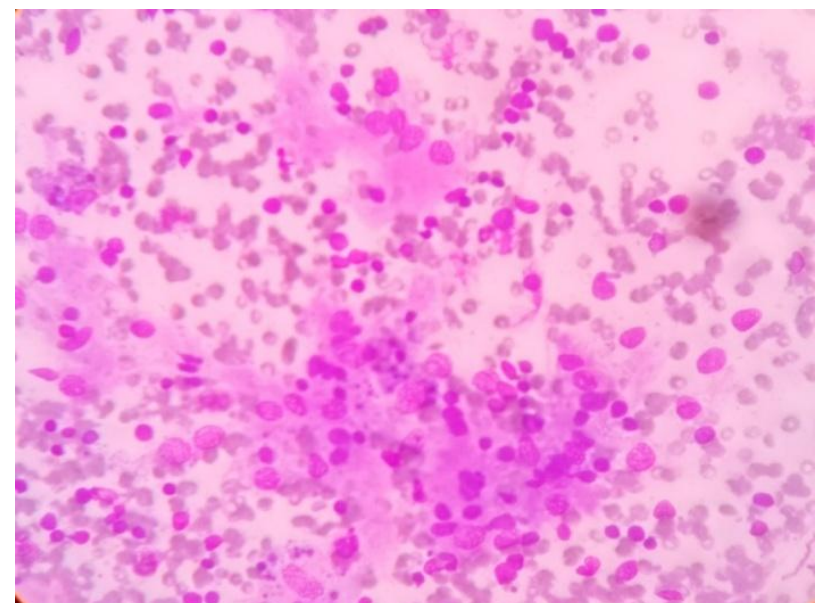

Figure 2: (b) Granulomatous (subacute) thyroiditis. Photomicrograph showing clusters of epithelioid histiocytes mixed with benign follicular cells (Smear, Giemsa, 400x magnification).

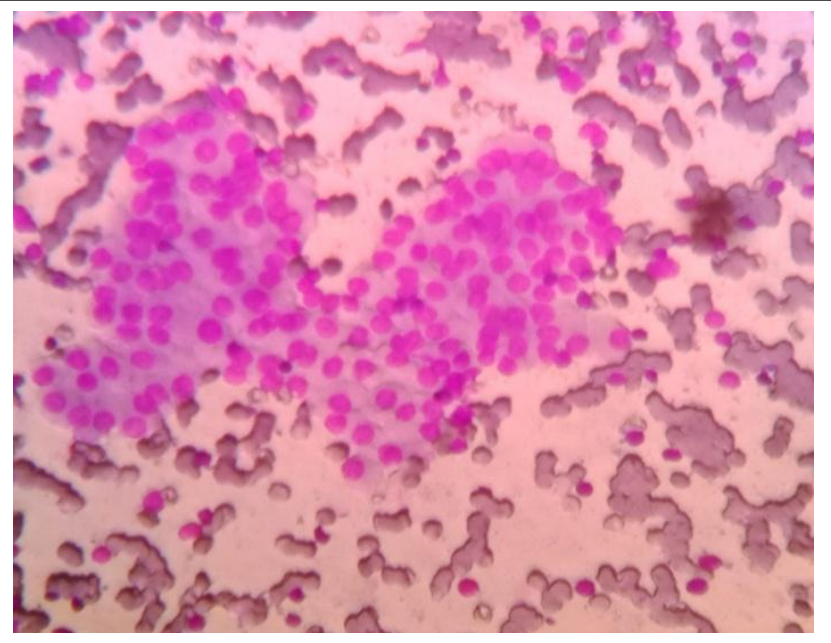

Figure 3: (a) Hurthle cell neoplasm. Photomicrograph showing clusters of hurthle cells(Smear, Giemsa, 400x magnification).

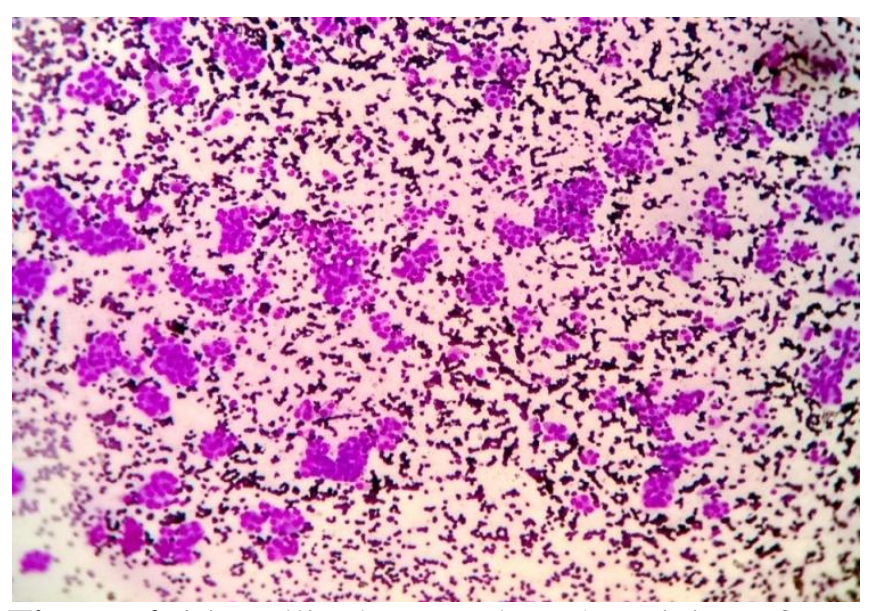

Figure 4 (a) Follicular neoplasm/suspicious for a follicular neoplasm. Photomicrograph showing a highly cellular aspirate composed of uniform follicular cells arranged in crowded clusters and microfollicles (Smear, Giemsa, 100x magnification).

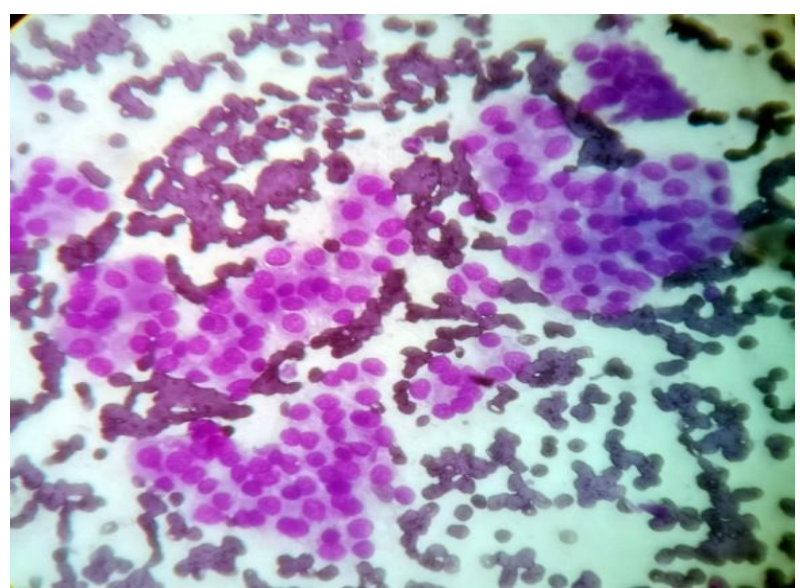

Figure 4 (b) Follicular neoplasm/suspicious for a follicular neoplasm. Photomicrograph showing a highly cellular aspirate composed of uniform follicular cells arranged in crowded clusters and 
microfollicles (Smear, Giemsa, 400x magnification).

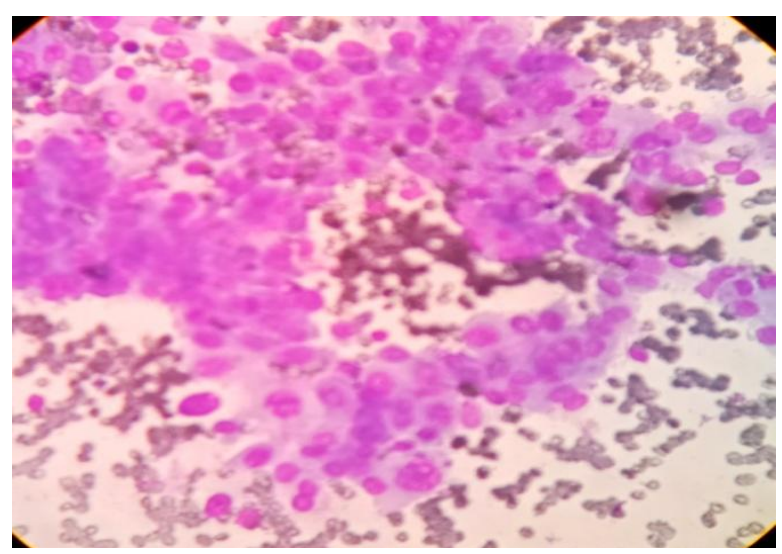

Figure 5: (a) Papillary thyroid carcinoma. (d) Papillary thyroid carcinoma. Photomicrograph showing longitudinal nuclear grooves (thin long arrow) and micronucleoli (thin short arrows).Intranuclear cytoplasmic inclusions are visible (Smear, Papanicolaou stain, 1000x magnification).

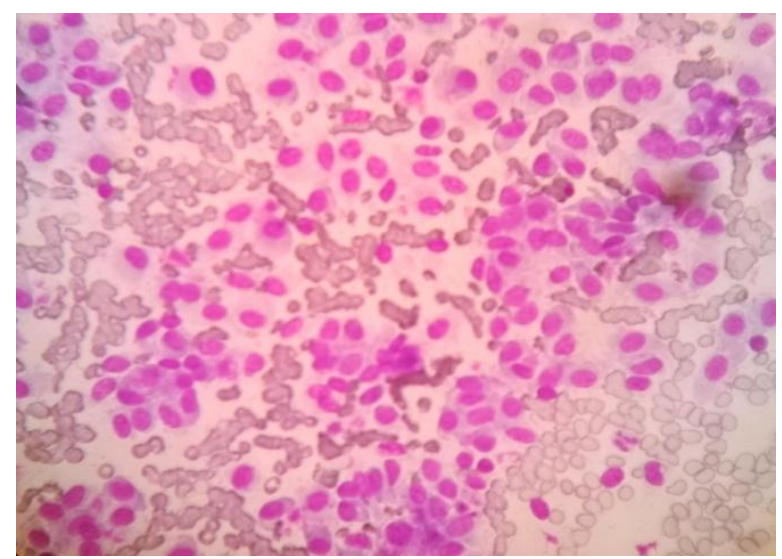

Figure 6: (a) (100x magnification) and (b) (1000x magnification) Medullary thyroid carcinoma. Photomicrographs showing predominantly cohesive, syncytial-like clusters with few isolated plasmacytoid cells (Smear, Giemsa stain).

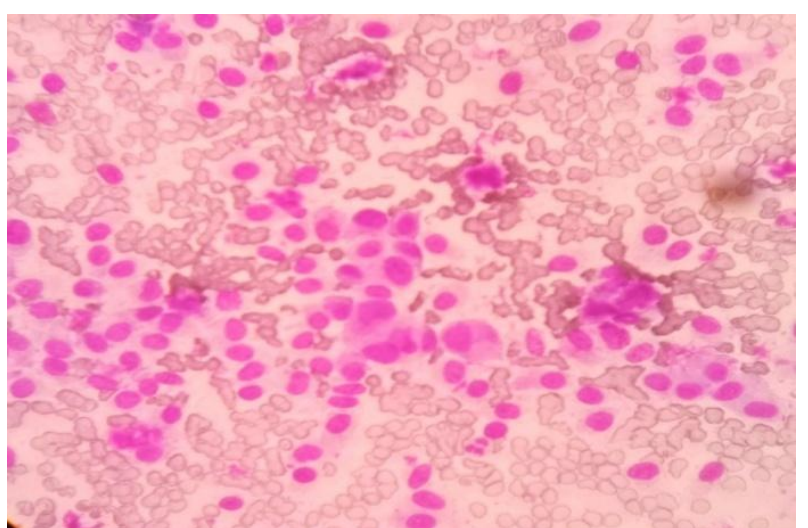

Figure 6: (b) (400x magnification) Medullary thyroid carcinoma. Photomicrographs showing predominantly cohesive, syncytial-like clusters with few isolated plasmacytoid cells (Smear, Giemsa stain).

\section{Discussion}

Thyroid swellings cause apprehension because their behaviour is unpredictable. ${ }^{[7]}$ Whether thyroid enlargement is diffuse or in the form of nodule; it has to be investigated to rule out the possibility of a neoplasm. ${ }^{[9]}$ FNA has proven to be an effective management tool in patients with thyroid nodules. Its main purpose is to provide a rational approach for management and determine the correct surgical procedure when surgery is required.

Various studies on thyroid diseases have estimated that about 42 million people in India suffer from thyroid disorders. ${ }^{[10]}$ The primary purpose of using FNAC and other available investigative aids like US examination, thyroid function tests, thyroid scan and antibody levels is to handpick the patients who can be treated surgically or conservatively.

The usage of different terminologies and diagnostic criteria is a result of lack of standardized system of reporting. This creates confusion amongst the clinicians pertaining to interpretation of the cytology report. This ultimately hampers a definitive clinical management. To overcome this issue, National Cancer Institute in the year 2007 proposed Bethesda System for Reporting Thyroid Cytopathology comprising of six diagnostic categories. ${ }^{[9]}$

In the present study, maximum numbers of cases were seen in the age group 20-40 years - 309 cases (50\%). Similar observations were seen by Parikh et $a l .^{[11]}$ and Singh et al. ${ }^{[12]}$ which included 57 cases $(23.75 \%)$ and 41 cases $(29.2 \%)$, respectively. However, Yassa et al. ${ }^{[13]}$ observed maximum number of cases between age group 41 and 50 years.

The sex distribution pattern of cases revealed maximum thyroid swellings were seen in female patients with M:F ratio being 1:7, which correlates with the observations made by Silverman et al. ${ }^{[14]}$ - 
1:10, Gupta et al. ${ }^{[15]}-1: 11$, Parikh et al. ${ }^{[11]}-1: 7$ and Yassa et al. ${ }^{[13]}-1: 7$.

In our study, maximum number of cases belonged to the benign category 457 cases $(74 \%), 4$ cases $(0.6 \%)$ belonged to suspicious for malignancy and 35 cases (5.6\%) belonged to malignant. However, in the study done by Guhamallick et al., ${ }^{[16]}$ a maximum number of cases belonged to benign 197 cases (79\%) which was concordant with our study, whereas in the study done by Singh et al. ${ }^{[12]}$ a maximum number of cases belonged to malignant, i.e., 70 cases $(57.3 \%)$ which was discordant with our study.

In the present study, 4 cases $(0.6 \%)$ were categorized into suspicious for malignancy which was concordant with the study done by Singh et al. ${ }^{[12]}$

Similar to the observations of Handa et al. ${ }^{[17]}$ and Binesh and Salari et al. ${ }^{[18]}$

In our study among 126 patients with lymphocytic thyroiditis, forty patients $(31.7 \%)$ had mild lymphocytic infiltration of the gland and were graded as Grade I thyroiditis. Sixty six patients (52.3\%) had grade II disease characterized by moderate degree of infiltrate with evidence of follicular destruction, Hurthle cell change, giant cells etc. Grade III thyroiditis was noted in 18 (14.28\%) patients who showed dense infiltrates with germinal centers andwith very few follicular cells left. The polymorphic population of cells with lymphocytes, immunoblasts and plasma cells helped in distinguishing these cases from Non-Hodgkin's lymphoma.. A study done in Department of Cytology, Postgraduate Institute of Medical Education and Research, Chandigarh, India by Bhatia et al. And Department of Pathology, Andhra Medical College, Visakhapatnam, by uma et al, ${ }^{(19)}$ reported similar findings.

On detailed assessment of cytomorphological features of colloid goiter in the present study, it was found that they have a variable morphology. The cellularity of smears ranged from low cellular to highly cellular with various epithelial arrangements of follicular cells like loose aggregates and lying singly, honeycomb flat sheets with aggregates, follicular arrangement, syncytial clusters and occasional papillary clusters. $86 \%$ of cases showed presence of thin colloid while the $14 \%$ cases had both thin and thick colloid. The important finding was presence of Hurtle cells in $14 \%$ cases and lymphocytes in the background of $18 \%$ of the cases. The intranuclear cytoplasmic inclusion was noted in 2 cases leading to the discordant diagnosis of papillary carcinoma thyroid.

In the present study carcinoma group comprised 38 cases $(6.1 \%)$, which were similar to the observations of Handa et al. ${ }^{[17]}$ and Binesh and Salari et al. ${ }^{[18]}$

Out of the total 619 cases, as per the six tier Bethesda system, 59 cases belonged to nondiagnostic/unsatisfactory - I Category, 457 cases belonged to benign - II Category, 20 cases were classified under atypia of undetermined significance - III Category, 51 cases belonged to follicular neoplasm/suspicious for follicular neoplasm - IV Category, 4 cases belonged to suspicious for malignancy - V Category, and 35 cases belonged to malignant - VI Category. The majority of cases 457 cases (74\%) were categorized into benign Category II in the present study which was concordant with the other studies conducted by $\mathrm{Wu}$ et al.(20) Yassa et $a l^{(13)}$ and Mondal et $a l^{(21)}$. The distribution of cases as per the six-tier Bethesda system in our study differed from that of other studies. Jo et al. ${ }^{[22]}$ Kini et al., described six parameters for PTC: Papillary tissue fragments, monolayer sheets of follicular cells, INCI, NG, tissue fragments with or without a follicular pattern, and large multinucleated foreign body-type of giant cells in the absence of degenerative changes. According to $\mathrm{Wu}$ et al ${ }^{(20)}$., the most commonly cited cytology criteria for PTC were flat syncytial sheets, nuclear enlargement, fine chromatin, NG, INCI, and some amount of colloid. Castro-Gomez et $a l^{(23)}$ described 15 cytology features of PTC in FNA smears of thyroid: Tridimensional fragments, papillae, anisonucleosis, nuclear bars (grooves), INCI, powdery chromatin, vacuolated cytoplasm, metaplastic cytoplasm, PB, autolysis, multinucleated giant cells, spindle cells, colloid, monolayer lamina, and macrophages. Kumar et al. suggested cellular swirls in cytology smears are highly specific for PTC. Despite these welldefined cytology features, diagnostic difficulties do exist in FNA smears while making decision in respect to PTC cases. 
Cytomorphologic Features Present in All Cases of Medullary Thyroid Carcinoma included in this study are binucleation and multinucleation, eccentric nuclei, neuroendocrine like chromatin. Inconspicuous nucleoli, ill-defined cell borders and clean background similar to the study of syed et al, Verma k et al.

In our study, anaplastic carcinoma comprised $10.5 \%$ of all thyroid carcinomas which is more than in the studies done by Caccanjaeu et $\mathrm{al}^{(28)}$ and $\mathrm{Nel} \mathrm{C} \mathrm{J} \mathrm{et} \mathrm{al}{ }^{(29)}$ who found the incidence to be $3 \%$ $5 \%$ of all thyroid carcinoma and similar to study of ghosh et $\mathrm{al}^{(27)}$ where incidence of anaplastic carcinoma is $11.9 \%$. In our study, 2 cases had muscle infiltration and all cases each with lymphatic emboli and cervical lymphadenopathy. This is in concordance with the study conducted by Ghosh et al.

Among 617 cases 23 cases were thyroidectomy specimens.. The histological data from 23 operated cases out of 619 patients in which $33.3 \%$ were malignant and $67.7 \%$ were benign. The most common variety was lymphocytic thyroiditis and colloid goitre followed by papillary carcinoma and medullary carcinoma. This study is corroborated with Halbhavi SN et al ${ }^{(30)}$ who studied 22 operated cases out of 60 patients in which $3.33 \%$ were malignant and $33.33 \%$ were benign.

\section{Conclusion}

FNAC is regarded as a minimally invasive, costeffective technique with diagnostic accuracy in the range of $90-99 \%$. The task of convincing clinicians of the value of the technique has been extremely successful since their expectations of a high level of accuracy have been met. FNAC is the test of choice for the triage of patients requiring surgery, thus avoiding approximately $80 \%$ of all thyroid surgery. The conclusion drawn from this study implicates FNAC as a useful primary investigative modality for evaluation of palpable thyroid nodules. It also helps in distinguishing lesions based on the treatment required.
TBSRTC aids in accurate cytological diagnosis. An effective implementation of this system would allow consistency in reporting of diagnostic terminologies between the cytopathologists and clinicians. Apart from this; it would also result in formulating a consistent management approach toward various thyroid related lesions.

\section{References}

1. Mehra. P , Verma A.K .Thyroid Cytopathology Reporting by the Bethesda System: A Two-Year Prospective Study in an Academic Institution .Pathology Research International Volume 2015, Article ID 240505, 11 pages.

2. Hamberger B, Gharib H, Melton LJ III, et al. Fine-needle aspiration biopsy of thyroid nodules: impact on thyroid practice and cost of care. Am J Med. 1982;73:381-384.

3. Yassa L, Cibas ES, Benson CB, et al. Long-term assessment of a multidisciplinary approach to thyroid nodule diagnostic evaluation. Cancer. 2007;111:508-516.

4. A. Gopinathan , A.Hegde, and F.H. V.Chong. Thyroid nodules: risk stratification for malignancy with ultrasound and guided biopsy.2011; 11(1): 209-223.

5. S. Z. Ali and E. S. Cibas, Eds., The Bethesda System for Reporting Thyroid Cytopathology. Definitions, Criteria and Explanatory Notes, Springer, New York, NY, USA, 2010.

6. A. Zajdela, M. A. de Maublanc, P. Schlienger, and C. Haye, "Cytologic diagnosis of orbital and periorbital palpable tumors using fine-needle sampling without aspiration," Diagnostic Cytopathology, vol. 2, no. 1, pp. 17-20, 1986.

7. Bibbo M. Comprehensive Cytopathology. 2nd ed. Philadelphia, PA: W.B. Saunders Company; 1997. p. 673. 
8. Tagore.S., Jayaprakash H. T., Sasidharan. A, Nagaraj T, Santosh H. N., Balraj .L. Cytological study of thyroid lesions by fine-needle aspiration cytology. Journal of Medicine, Radiology, Pathology \& Surgery (2016), 2, 12-15

9. Jo VY, Stelow EB, Dustin SM, Hanley KZ. Malignancy risk for fine-needle aspiration of thyroid lesions according to the Bethesda System for Reporting Thyroid Cytopathology. Am J Clin Pathol 2010;134:450-6.

10. Bommanahalli BP, Bhat RV, Rupanarayan R. A cell pattern approach to interpretation of fine needle aspiration cytology of thyroid lesions: A cyto-histomorphological study. J Cytol 2010;27:127-32.

11. Parikh UR, Goswami HM, Shah AM, Mehta NP, Gonsai RN. Fine needle aspiration cytology (FNAC) study of thyroid lesions (study of 240 cases). Gujarat Med J 2012;67:25-30.

12. Singh DK, Kumar R, Paricharak SD, Nigam N, Nigam SK. Role of fine needle aspiration cytology in solitary thyroid nodules. J Evol Med Dent Sci 2013;36:6903-14.

13. Yassa L, Cibas ES, Benson CB, Frates MC, Doubilet PM, Gawande AA, et al. Long-term assessment of a multidisciplinary approach to thyroid nodule diagnostic evaluation. Cancer 2007;111:508-16.

14. Silverman JF, West RL, Larkin EW, Park HK, Finley JL, Swanson MS, et al. The role of fine-needle aspiration biopsy in the rapid diagnosis and management of thyroid neoplasm. Cancer 1986;57:116470.

15. Gupta M, Gupta S, Gupta VB. Correlation of fine needle aspiration cytology with histopathology in the diagnosis of solitary thyroid nodule. J Thyroid Res 2010;2010:379051.
16. Guhamallick M, Sengupta S, Bhattacharya NK. Cytodiagnosis of thyroid lesionsusefulness and pitfalls: A study of 288 cases. J Cytol 2008;25:6-9.

17. Handa U, Garg S, Mohan H, Nagarkar N. Role of fine needle aspiration cytology in diagnosis and management of thyroid lesions: A study of 434 patients. J Cytol 2008;25:13-7.

18. Binesh F, Salari AA. Comparative evaluation of the diagnosis results of fineneedle aspiration cytology and pathology in the assessment of thyroid nodules. Pak $\mathbf{J}$ Med Sci 2008;24:382-5.

19. Rajwanshi Arvind, Radharaman J D, Mittal BR, Saxena AK, Bhatia A.Lymphocytic thyroiditis - is cytological grading significant? A correlation of grades with clinical, biochemical, ultrasonographic and radionuclide parameters.

20. Wu HH, Rose C, Elsheikh TM. The Bethesda system for reporting thyroid cytopathology: An experience of 1,382 cases in a community practice setting with the implication for risk of neoplasm and risk of malignancy. Diagn Cytopathol 2012;40:399-403.

21. Mondal SK, Sinha S, Basak B, Roy DN, Sinha SK. The Bethesda system for reporting thyroid fine needle aspirates: A cytologic study with histologic follow-up. J Cytol 2013;30:94-9.

22. Jo VY et al, Stelow EB, Dustin SM, Hanley KZ. Malignancy risk for fineneedle aspiration of thyroid lesions according to the Bethesda System for Reporting Thyroid Cytopathology. Am J Clin Pathol 2010;134:450-6. 
23. Gomez et al,Ramirez et al.Cytologic Criteria of Cystic Papillary Carcinoma of the Thyroid. 47(4):590-4 · July 2003.

24. Chandanwale S.S et al, Kumar $\mathrm{H}$ et al, Buch A et al, Soraisham.P et al. Papillary thyroid carcinoma, a diagnostic approach in fine needle aspiration: Review of literature.Year : 2013 | Volume : 2 | Issue : 4 | Page : 339-343

25. Green I et al, .Syed Z. Ali et al. Elizabeth A. A et al, Zakowski M F et al .A spectrum of cytomorphologic variations in medullary thyroid carcinoma.

26. Bose $\mathrm{S}$ et al, Kusum K et al, verma k et al. Medullary carcinoma of the thyroid: A cytological, immunocytochemical, and ultrastructural study. Volume8, Issue1. January 1992.Pages 28-32.

27. Ghosh et al, Nepal et al, Gharti et al, Basnet et al, Baxi et al, Talwar et al.anaplastic carcinoma of thyroidclinicomorphological spectrum and review of literature.Journal of Pathology of Nepal (2011) Vol. 1,45-48.

28. Carcangiu ML, Steeper T, Zampi G, Rosai J. Anapalstic thyroid carcinoma: A study of 70 cases. Am J Clin pathol 1985;83:135-58.

29. Nel CJ, van Heerden JA, Goellner JR. Anaplastic carcinoma of the thyroid: a clinicopthologic study of 82 cases. Mayo Clin Proc 1985;60:51-8.

30. Halbhavi SN, GanjigattiM, Kuntoji SB, Mohammedgouse A. Karikazi. Clinicopathological study of thyroid swellings in HSK hospital in Karnataka, India . Int Surg J. 2018 Feb;5(2):420-425. 